\title{
Effect of Non-Solvents Used in the Coagulation Bath on Morphology of PVDF Membranes
}

\author{
Mônica Beatriz Thürmer ${ }^{\mathrm{a} *}$, Patrícia Poletto ${ }^{\mathrm{b}}$, Marcos Marcolin $^{\mathrm{b}}$, Jocelei Duarte $^{\mathrm{b}}$, Mara Zeni $^{\mathrm{b}}$ \\ ${ }^{a}$ Materials Engineering Department, Universidade Federal do Rio Grande do Sul - UFRGS, \\ CEP 91501-970, Porto Alegre, RS, Brasil \\ ${ }^{\mathrm{b} S}$ Science and Technology Center, Universidade de Caxias do Sul - UCS, Caxias do Sul, RS, Brasil
}

Received: February 28, 2012; Revised: May 23, 2012

\begin{abstract}
The aim of this paper was to prepare a poly (vinylidene fluoride) (PVDF) membrane using different non-solvents in the coagulation bath for the phase inversion method. In order to increase the mechanical strength of membranes, facing the pressure of work, was used a macro-porous polyester support. The morphology and structure of the resulting membranes were evaluated by scanning electron microscopy, porosity measurements, water and 1-octanol uptake, contact angle, pure water flux, hydraulic permeability and hydraulic resistance. The morphology and pure water flux changed significantly using ethanol (symmetric membrane) and/or water (asymmetric membrane) as the non-solvent. The symmetric membrane presented a high hydrophobic surface (water contact angle $\sim 136^{\circ}$ ) and a higher pure water flux and porosity than the asymmetric membrane, which presented a lower hydrophobicity surface (water contact angle $\sim 90^{\circ}$ ). The morphologies obtained suggest different applications.
\end{abstract}

Keywords: contact angle, hydrophobicity, immersion-precipitation, poly (vinylidene fluoride), supported membrane

\section{Introduction}

Membrane processes are increasingly important to treat drinking water and wastewater. Substantial advances in the preparation of membranes and the composition of membrane materials have led to this breakthroughs ${ }^{1}$. The cost of membranes continues to fall and it is possible to predict that membranes will be in wide use in water treatment facilities ${ }^{2}$.

Poly (vinylidene fluoride) (PVDF) is a very attractive polymer, exhibiting chemical and mechanical resistances, widely used at to synthesize a lot of membrane operations ${ }^{3}$.

The key advantages of PVDF include its highly hydrophobic nature and excellent chemical resistance against corrosive chemicals such as acids, bases, oxidants and halogens. Typically, PVDF comprises crystalline phases along with amorphous and/or rubbery regions which respectively provide the thermal stability and flexibility of the membranes. Compared to other hydrophobic materials such as poly (tetrafluoroethylene) (PTFE) and polypropylene (PP), PVDF has better processability since it is soluble in common organic solvents ${ }^{4}$. With these superior properties, PVDF has been considered for utilization in various membrane-based separations e.g. micro/ultra/nano-filtration ${ }^{5,6}$, membrane distillation ${ }^{7-9}$, pervaporation $^{10}$ and membrane gas absorption ${ }^{11,12}$.

The phase inversion technique is commonly used to prepare PVDF membranes. Membrane precipitation is induced by means of liquid-liquid demixing and/or crystallization. The membranes formed often exhibit characteristics from both types of phase separations, cellular pores or interlinked crystalline particles ${ }^{3}$.

*e-mail: monicathurmer@yahoo.com.br
In the phase inversion process, there are many preparation parameters affecting polymer precipitation and ultimately the morphology of the formed membrane. The polymer concentration, the use of additives ${ }^{13-15}$, the solvent ${ }^{14}$, the composition and the temperature of the coagulation bath $^{3,16,17}$, the composition of the casting solution ${ }^{13,18}$ and the temperature of the casting solution ${ }^{19,20}$ are the most influential and the most frequently discussed in the literature.

The hydrophobic PVDF membranes are extensively used for water treatments as a form of flat sheet or of hollow fiber, because the membrane offers high void volumes, has well defined porosity and it is chemically inert ${ }^{21}$. Kuo et al. ${ }^{22}$ investigated the permeation flux and rejection coefficient of the porous PVDF membranes with different hydrophobicity, in a direct contact membrane distillation system and obtained high permeation flux and high salt rejection coefficient which were close to the commercial membrane.

In the present study we have focused our attention on the effect of non-solvents on the morphology, hydrophobicity and pure water flux of the PVDF membranes. The PVDF membranes obtained were characterized by density, porosity, water contact angle, pure water flux, hydraulic permeability, hydraulic resistance and scanning electron microscope (SEM).

\section{Experiment}

\subsection{Materials}

Poly (vinylidene fluoride) (PVDF) SOLEF 1015/0078 was purchased from Solvay Solexis, Inc. The solvent used in the preparation of membrane was NN'-dimethylformamide 
(DMF) from Vetec. The non-solvents used were distilled water and ethanol from Simoquímica. The support used was woven macroporous $100 \%$ polyester with a thickness of $180 \mu \mathrm{m}$ purchased from Notredame Trade and Imports.

\subsection{Membrane preparation}

Membranes were prepared by the immersion precipitation method. The dope solution was prepared at $60 \pm 2{ }^{\circ} \mathrm{C}$ by dissolving the PVDF (20 wt. (\%)) in DMF (80 wt. (\%)) for 24 hours. The polymer solution (with $0.2 \mathrm{~mm}$ of thickness) was cast on polyester support on a glass plate and was immersed into a coagulation bath. Two types of non-solvents were used to prepare the A and B membranes. The non-solvent utilized in the A membrane coagulation bath was only deionized water for 4 hours. The B membrane was immersed into ethanol for 2 seconds, and then was immersed into water coagulation bath for 4 hours. After precipitation, the membranes were dried at room temperature for 48 hours.

\subsection{Membrane characterization}

\subsubsection{Scanning electron microscope (SEM)}

The membrane morphology was examined by a Shimadzu (Model SSX-550) scanning electron microscope (SEM). In SEM studies, the PVDF membrane was carefully removed from the support (because it was not possible to fracture the support) and the sample was fractured in liquid nitrogen and coated with Au by sputtering.

\subsubsection{Density of the membranes}

Membrane density was determined according to ASTM D792-08 ${ }^{23}$. Membrane density can be related to membrane porosity.

\subsubsection{Porosity}

The method used to determine porosity was proposed by Wang et al. ${ }^{24}$ The porosity was measured by soaking the membrane into 1-octanol for 2 hours and then the membrane surface was dried by filter paper. The membrane was weighed before and after absorption of the 1-octanol. The porosity was calculated using Equation 1.

$$
\varepsilon=\frac{m_{b} / \rho_{b}}{m_{b} / \rho_{b}+m_{p} / \rho_{p}} \times 100
$$

where $\varepsilon$ is the porosity of the membrane $(\%), m_{p}$ is the mass of membrane $(\mathrm{g}), m_{b}$ is the mass of absorbed 1-octanol $(\mathrm{g})$, $\rho_{p}$ is the density of membrane $\left(\mathrm{g} \cdot \mathrm{cm}^{-3}\right)$, and $\rho_{b}$ is the density of 1-octanol $\left(\mathrm{g} \cdot \mathrm{cm}^{-3}\right)$.

\subsubsection{Water and 1-octanol uptake measurements}

The water uptake (WU) and 1-octanol uptake (OU) were determined by soaking the membrane samples in deionized water and 1-octanol, respectively and separately, until it reached the condition of sample saturation, at $25 \pm 2{ }^{\circ} \mathrm{C}$. Samples were removed and the excess liquid adhered to both sides of their surface was quickly blotted by filter paper. The water uptake and the 1-octanol uptake were determined as the weight gain of the membrane in the wet state compared to the dry state using Equation 2.
$W U \operatorname{orOU}(\%)=\frac{W_{w}-W_{d}}{W_{d}} \times 100$

where $\mathrm{W}_{\mathrm{w}}$ is weight of wet membranes $(\mathrm{g})$ and $W_{d}$ is weight of dry membrane $(\mathrm{g})$.

The same equation is used for both calculations. These tests, along with water contact angle measurement were used for the purpose of verifying the hydrophobicity of the membranes.

\subsubsection{Water contact angle measurement}

Water contact angle of membrane surface was measured by using the sessile drop method, and all the contact angle data were an average of five measurements on different locations of membrane surface. A water droplet was introduced on the surface of membranes, and the contour of the water drop was recorded.

In this method, by optical microscopy, we obtain the profile of a drop deposited on a horizontal surface. The image profile of the drop obtained by the digital camera is analyzed by software (Surftens) adjusting the diameter of the drop and the contact angle with the surface. The shape of the drop deposited on a surface is determined by the interaction of three forces that are positioned along the contact line formed by each pair of the three phases: the line between solid and liquid phase $\left(\gamma_{S L}\right)$, between solid and vapor phase $\left(\gamma_{S V}\right)$, and between the liquid and vapor phase $\left(\gamma_{L V}\right)$, as in Figure 1. All three forces define the overall shape of the drop, and the surface tension (energy per unit area).

The contact angle $\theta$, formed between $\gamma_{S L}$ and $\gamma_{L V}$, is obtained by the equation of Young and Dupré (Equation 3), under steady state condition ${ }^{25-27}$.

$\cos \theta=\left(\frac{\gamma_{S V}-\gamma_{S L}}{\gamma_{L V}}\right)$

The surfaces where $\theta<90^{\circ}$ are classified as hydrophilic, and those with contact angle $90^{\circ}<\theta<150^{\circ}$ hydrophobic and superhydrophobic, considered in the static sense, if $\theta>150^{\circ[28]}$.

\subsubsection{Normalized flux}

The permeated flux of water through the membranes was normalized to the temperature of $20^{\circ} \mathrm{C}$, considering the coefficient of permeability of the membrane as a constant. The normalization was calculated using Equation 4.

$J_{20}=\left(\frac{\eta_{T}}{\eta_{20}}\right) . J_{T}$

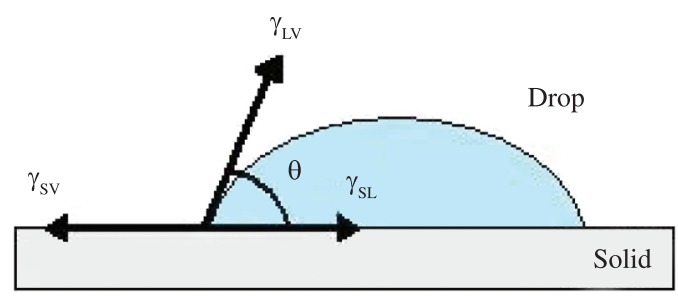

Figure 1. Forces acting on a drop deposited on a solid surface. 
where $J_{20}$ is the membrane flux in the temperature of $20^{\circ} \mathrm{C}$ $\left(\mathrm{L} / \mathrm{m}^{2} \mathrm{~h}\right), J_{T}$ is the membrane flux at temperature $\mathrm{T}\left(\mathrm{L} / \mathrm{m}^{2} \mathrm{~h}\right)$, $\eta_{20}$ is the dynamic viscosity of the water at a temperature of $20{ }^{\circ} \mathrm{C}\left(\mathrm{N} . \mathrm{s} / \mathrm{m}^{2}\right)$ and $\eta_{T}$ is the dynamic viscosity of the water at temperature $\mathrm{T}\left(\mathrm{N} . \mathrm{s} / \mathrm{m}^{2}\right)$.

\subsubsection{Compaction}

The prepared PVDF membranes were compacted with deionized water at 9 bar until stable flux in a permeation system of $0.063 \mathrm{~m}^{2}$ area.

\subsubsection{Pure water flux, hydraulic permeability (Pm) and hydraulic resistance $\left(\mathrm{R}_{\mathrm{m}}\right)$}

After compactation, the pure water flux at different transmembrane pressures (ranging 0-9 bar) were measured under steady state condition using Equation 5.

$J_{w}=\frac{V}{A \cdot \Delta T}$

where $J_{w}$ is pure water flux $\left(\mathrm{L} / \mathrm{m}^{2} \mathrm{~h}\right), V$ is the volume of permeate $(\mathrm{L}), A$ is effective membrane area $\left(\mathrm{m}^{2}\right)$ and $\Delta T$ is sampling time (h).

Hydraulic permeability was calculated from the slope of linear relationship between the pure water flux $\left(\mathrm{J}_{\mathrm{w}}\right)$ and transmembrane pressure, using Equation 6.

$P_{m}=\frac{J_{w}}{\Delta P}$

where $P_{m}$ is hydraulic permeability $\left(\mathrm{L} / \mathrm{m}^{2} \mathrm{~h}\right.$.bar) and $\Delta P$ is transmembrane pressure (bar).

The membrane resistance was evaluated from the slope obtained by plotting water flux versus transmembrane pressure difference, using Equation 7.

$R_{m}=\frac{\Delta P}{J_{w}}$

where $R_{m}$ is membrane hydraulic resistance (bar.m $\mathrm{m}^{2} . \mathrm{h} / \mathrm{L}$ ), $\Delta P$ is transmembrane pressure (bar) and $J_{w}$ is pure water flux $\left(\mathrm{L} / \mathrm{m}^{2} \mathrm{~h}\right)$.

\section{Results and Discussion}

\subsection{Scanning Electron Microscope (SEM)}

SEM micrographs of the A membrane coagulated in pure water bath and B membrane coagulated in ethanol and in pure water at room temperature are shown in Figure 2. To evaluate the structure of membranes by SEM, it was necessary to remove the macroporous support to enable the cryogenic fracture of the samples. The skin membranes obtained from the different non-solvents coagulation bath, presented greater differences caused by the variation of the coagulation bath.

The A membrane exhibit an asymmetric structure showed in Figure 2a-c. A dense thin top layer was formed, namely "skin" on the surface, and a sponge-like structure was observed in the sublayer of resulting membrane.

The membrane coagulated in ethanol for 2 seconds and then immersed in pure water (Figure 2d-f) presented a symmetric structure, without a dense top layer. The B membrane exhibits a porous structure throughout the cross section. Concerning PVDF membranes, Bottino et al. ${ }^{29}$ reported that the cavities are separated by walls composed of discrete polymer globules. The porous sublayer structure, presented by the B membrane, is globular and the size of globules appears to be fairly uniform over the entire membrane cross section.

The morphologies presented in this work, was similar to those observed by Yong et al. ${ }^{30}$ where the PVDF membrane precipitated from water (harsh bath) exhibited an asymmetric structure and using 1-octanol (soft bath) in the coagulation bath, the membrane presented a uniform microporous structure, composed of spherical particles.

Li et al. ${ }^{31}$ attributed the morphology obtained in the B membrane, to the coagulation ability of the coagulant. Ethanol $\left(\Delta \delta_{\mathrm{c}-\mathrm{p}}=10.94 \mathrm{MPa}^{1 / 2}\right)$ presents poorer coagulation ability than water $\left(\Delta \delta_{c-p}=33.43 \mathrm{MPa}^{1 / 2}\right)$ for PVDF solution. The weakened coagulation ability slows the precipitation rate during the immersion process. Coagulation plays an important role in the formation of membranes by phase inversion processes. According to Tomaszewska ${ }^{32}$, porous structure, like a sponge type, which was observed in $\mathrm{B}$ membrane, is formed by a slow coagulation. In other hand, when an instantaneous coagulation occurs, a dense skin layer is formed.

According to some authors ${ }^{30,33}$, a dense top layer observed in A membrane, is formed because solvent in the casting solution desolvates into the coagulation bath before the coagulant diffuses into the casting solution. The dense top layer stops growing when enough coagulant medium diffuses into the sublayer solution to create pores. On the other hand, if the coagulant medium diffuses into the casting solution before solvent in the casting solution desolvates into the coagulation bath, the coagulant medium may create pores in the membrane surface. The porous surface occurs when a high ratio of the non-solvent inflow compared to the solvent outflow.

\subsection{Density, porosity and thickness of the membranes}

The porosity of each membrane was calculated using Equation 1 and they are reported in Table 1. The difference of porosity may be explained by variation of the non-solvent used in the coagulation bath. The porosity of A membrane prepared using water as coagulation bath was lower than B membrane prepared using ethanol and than water. The porosity difference was small because it takes the entire membrane structure into account, not only the top layer. Studies indicate that in general the top layer thickness of the membrane increases and the porosity decreases with increasing molar volume of the external non-solvent species, due to their lower diffusion rate ${ }^{3}$. However Lin et al. ${ }^{34}$ found the opposite result, as well as the results found in

Table 1. Properties of PVDF membranes prepared in different non-solvent coagulation baths.

\begin{tabular}{cccc}
\hline Membrane & $\begin{array}{c}\text { Density } \\
\left(\mathbf{g . c m}^{-3}\right)\end{array}$ & $\begin{array}{c}\text { Porosity } \\
(\boldsymbol{\%})\end{array}$ & $\begin{array}{c}\text { Thickness } \\
(\boldsymbol{\mu m})\end{array}$ \\
\hline A & $1.37 \pm 0.02$ & $48.54 \pm 0.74$ & $276 \pm 5$ \\
B & $1.39 \pm 0.02$ & $52.23 \pm 0.38$ & $296 \pm 7$ \\
\hline
\end{tabular}


our present study, which were attributed to a stronger interaction between the polymer and the non-solvent (i.e. thermodynamic factors). The difference found between the $\mathrm{A}$ and $\mathrm{B}$ membrane morphology and the absence of the dense top layer is shown in Figure 2.

The density of A membrane was slightly lower than B membrane, however this small difference, may be disregarded. The contribution of the PVF fraction was small, because the measures were carried out to the supported membranes (PVDF + polyester support).

\subsection{Water and 1-octanol uptake measurements and water contact angle measurement}

The water and 1-octanol uptake maximum and the average contact angle of the membranes prepared are reported in Table 2. This test was carried out in order to verify the greater hydrophobicity of the B membrane, as expected, according to the literature ${ }^{22}$. The condition of sample saturation in water occurred within 48 hours. For the samples in 1-octanol this was observed within 24 hours.

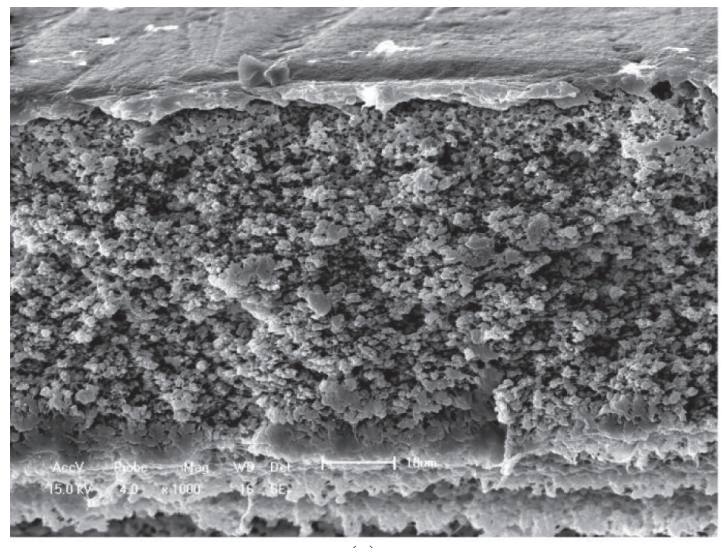

(a)

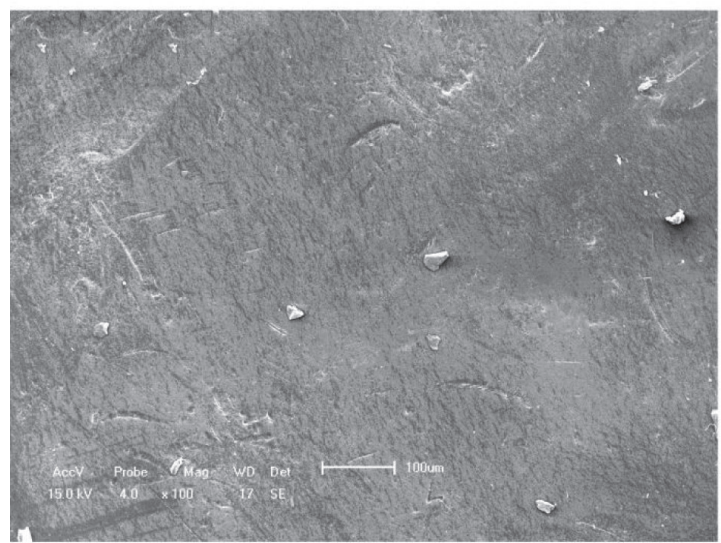

(c)

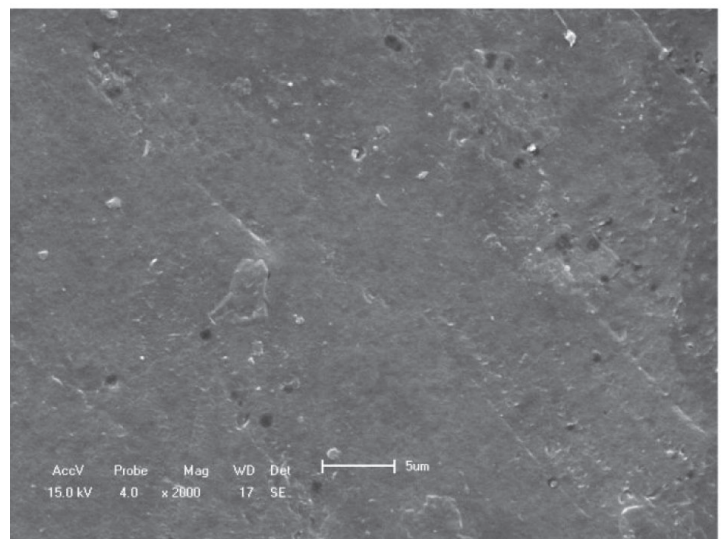

(e)

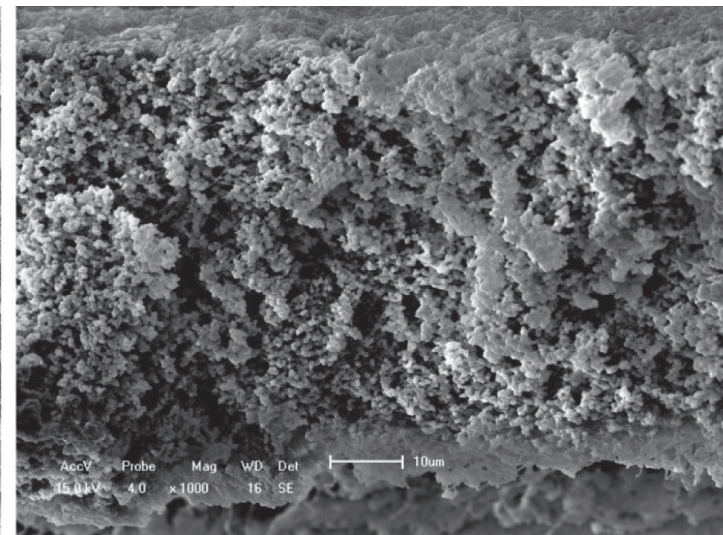

(b)

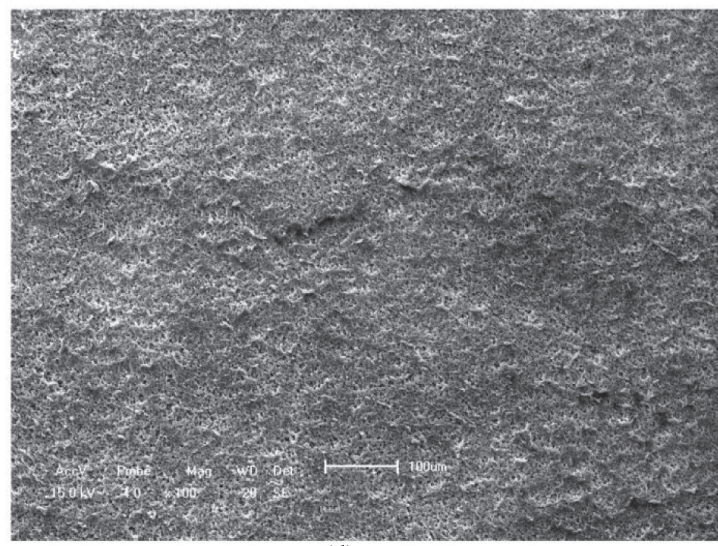

(d)

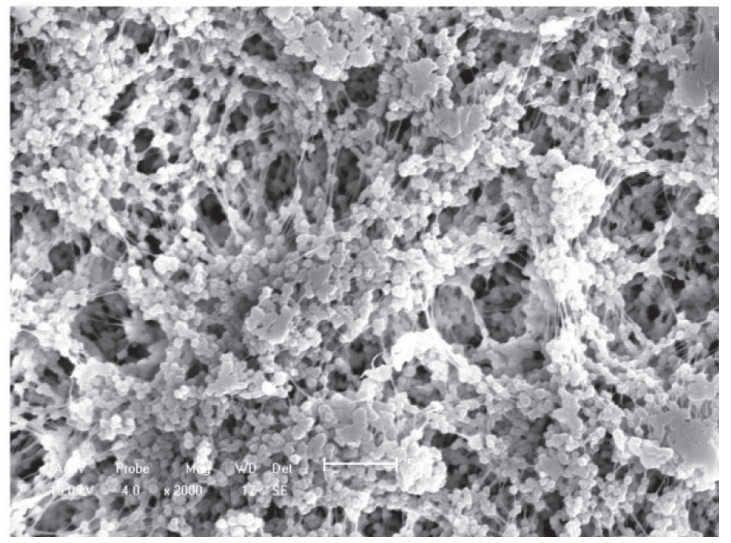

(f)

Figure 2. SEM micrographs of PVDF membranes: cross section (1000x) of A membrane (a) and B membrane (d); surface (100x) of A membrane (b) and B membrane (e); surface (2000x) of A membrane (c) and B membrane (f). 


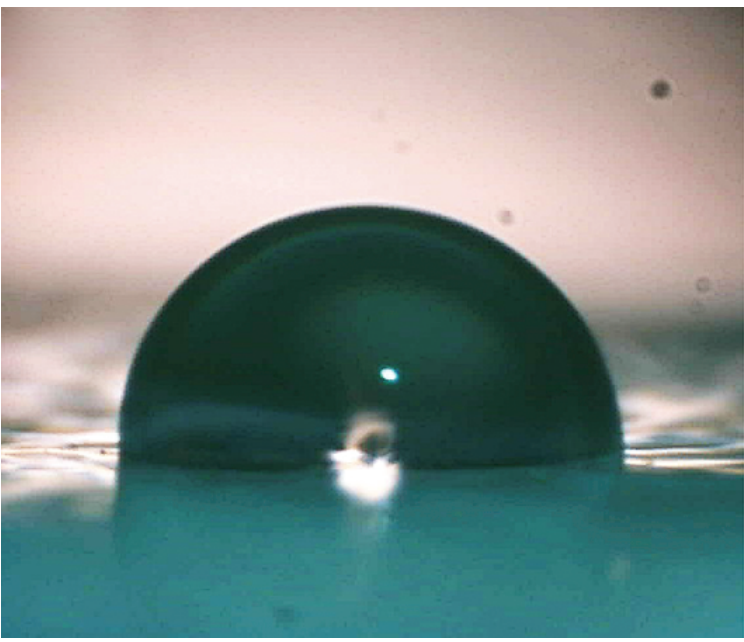

(a)

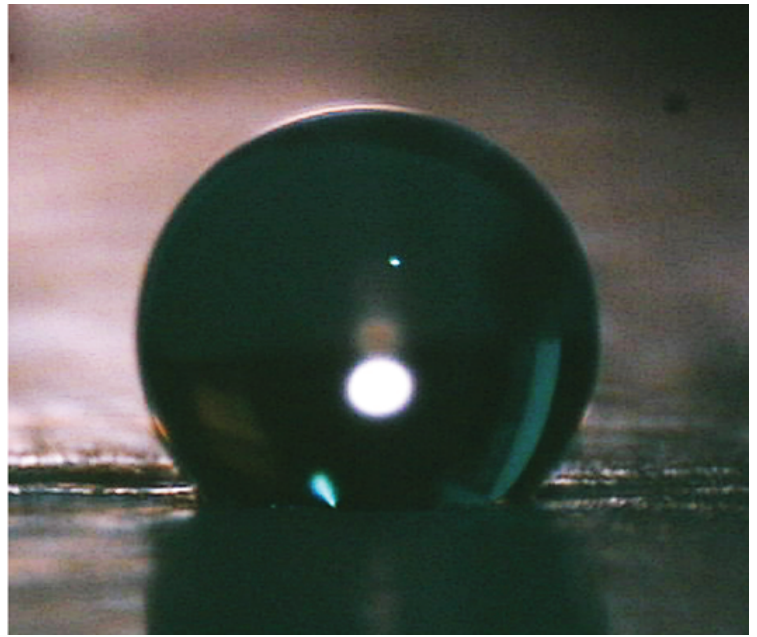

(b)

Figure 3. Water contact angle measurement of the A and B PVDF membranes, respectively.

Evaluating the results of Table 2, the B membrane presented a lower water absorption capacity with higher porosity, thus proving that it is more hydrophobic than the A membrane. The A membrane presented lower porosity, but higher water absorption. This conclusion can also be evidenced by the contact angle measures, shown in Figure 3, where the B membrane (Figure $3 b$ ), is significantly more hydrophobic than the A membrane (Figure 3a). The higher hydrophobicity is also proved by the higher absorption of 1-octanol.

Li et al. ${ }^{31}$ concluded that hydrophobicity is related with the surface porosity for PVDF membrane. As discussed above, the use of ethanol, in the coagulation bath, increased the porosity of the surface, resulting in a membrane with greater hydrophobicity.

\subsection{Compaction and pure water flux}

The membranes were subjected to hydraulic compaction at a constant transmembrane pressure of 9 bar for 4 hours until a steady-state flux was attained. The water flux was calculated using Equation 5 from the experimental permeate flux rate measured at 5-minute intervals. Through the permeability experiments it was also possible observed that there was good adhesion between the support and PVDF film when the membrane was subjected to high operating pressures.

The effect of compaction time on the pure water flux for the A and B membranes is shown in Figure 4. It was observed that the pure water flux decreased gradually due to compaction with time and, after about 2 hours of compaction, it was reached a steady-state value. This is due to the fact that the pore walls become closer, denser and uniform resulting in reduction of pore size and flux during compaction ${ }^{35}$.

The higher flux presented by B membrane is due to the higher porosity as discussed in the preceding section.

Transmembrane pressure versus pure water fluxes are plotted as shown in Figure 5. In general, the pure water flux increases with increasing transmembrane pressure and the increase in the operating pressure increase the driving
Table 2. Water and 1-octanol uptake and contact angle measurement of the PVDF membranes.

\begin{tabular}{cccc}
\hline Membrane & $\begin{array}{c}\text { Contact angle } \\
\left({ }^{\circ}\right)\end{array}$ & $\begin{array}{c}\text { Water uptake } \\
(\boldsymbol{\%})\end{array}$ & $\begin{array}{c}\text { 1-octanol } \\
\text { uptake }(\boldsymbol{\%})\end{array}$ \\
\hline A & $90 \pm 2$ & $14.15 \pm 0.06$ & $56.44 \pm 0.15$ \\
B & $136 \pm 2$ & $9.86 \pm 0.06$ & $61.76 \pm 0.06$ \\
\hline
\end{tabular}

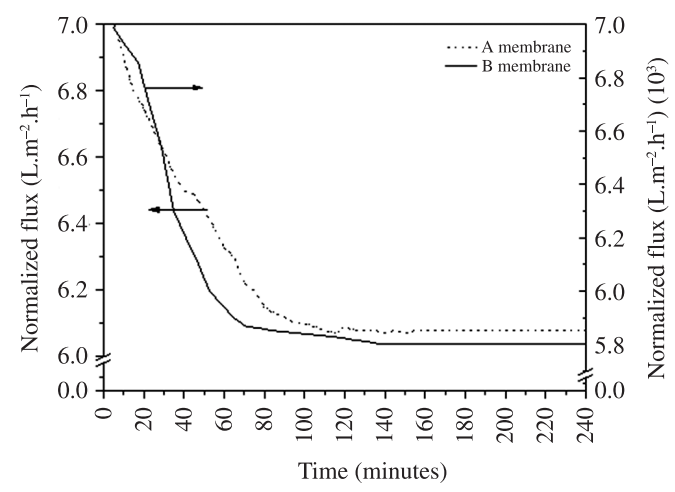

Figure 4. Effect of time on pure water flux of A and B PVDF membranes.

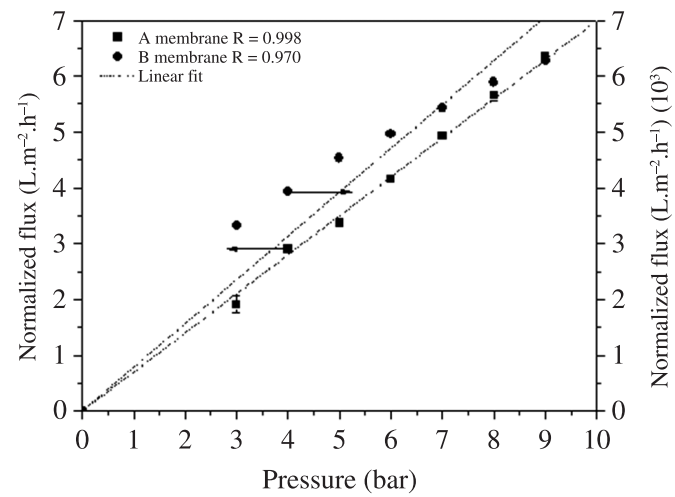

Figure 5. Effect of transmembrane pressure on pure water flux of $\mathrm{A}$ and $\mathrm{B}$ PVDF membranes. 
Table 3. Hydraulic permeability and hydraulic resistance of the PVDF membranes.

\begin{tabular}{ccc}
\hline Membrane & Pm (L/m $\mathbf{m}^{2} \mathbf{h}$. bar $)$ & Rm $\left(\right.$ bar.m $\left.^{2} . \mathbf{h} / \mathbf{L}\right)$ \\
\hline A & 0.70 & 1.43 \\
B & 784.9 & 0.0012 \\
\hline
\end{tabular}

force for water permeation. For example, the pure water flux at 8 bar to A membrane was $5.65 \mathrm{~L} / \mathrm{m}^{2} \mathrm{~h}$, while the B membrane was $5888.81 \mathrm{~L} / \mathrm{m}^{2} \mathrm{~h}$. This result indicates that the permeability is strong related with the pore formation from coagulation bath.

The correlation coefficient ( $R$ ) found for the B membrane $(0.970)$ is low but also shows a practically linear behavior.

\subsection{Hydraulic permeability $(P m)$ and membrane hydraulic resistance $\left(R_{m}\right)$}

Membrane hydraulic permeability is significant, particularly for membranes used in a pressure-driven separation process. Permeability was determined from the slope of the plots in Figure 5 using Equation 6 and is represented in Table 3. It was observed that the hydraulic permeability $(P \mathrm{~m})$ is higher in B membrane, which confirms that the $\mathrm{B}$ membrane is more porous than the $\mathrm{A}$ membrane.

Membrane hydraulic resistance $(\mathrm{Rm})$ is the intrinsic resistance of the membrane determined using pure water as feed and obtained by Equation $7^{[36]}$. The A membrane offers higher hydraulic resistance compared to B membrane. This result is in agreement with that of pure water flux experiments. The Rm of the membranes was calculated from the slope of the plot and given in Table 3. It was seen that

\section{References}

1. Buonomenna MG, Lopez LC, Favia P, Gordano A and Drioli E. New PVDF membranes: the effect of plasma surface modification on retention in nanofiltration of aqueous solution containing organic compounds. Water Research. 2007; 41:4309-4316. PMid:17631942. http://dx.doi. org/10.1016/j.watres.2007.06.033

2. Zuo X, Yu S, Xu X, Xu J, Bao R and Yan X. New PVDF organic-inorganic membranes: The effect of $\mathrm{SiO}_{2}$ nanoparticles content on the transport performance of anion-exchange membranes. Journal of Membrane Science. 2009; 340:206-213. http://dx.doi.org/10.1016/j.memsci.2009.05.032

3. Buonomenna MG, Macchi P, Davoli M and Drioli E. Poly(vinylidene fluoride) membranes by phase inversion: the role casting and coagulation conditions play in their morphology, crystalline structure and properties. European Polymer Journal. 2007; 43:1557-1572. http://dx.doi. org/10.1016/j.eurpolymj.2006.12.033

4. Sukitpaneenit P and Chung T-S. Molecular elucidation of morphology and mechanical properties of PVDF hollow fiber membranes from aspects of phase inversion, crystallization and rheology. Journal of Membrane Science. 2009; 340:192-205. http://dx.doi.org/10.1016/j.memsci.2009.05.029

5. Güell C and Davis RH. Membrane fouling during microfiltration of protein mixtures. Journal of the $\mathrm{Rm}$ of $\mathrm{B}$ membrane was the lowest in comparison to $\mathrm{A}$ membrane indicating that the pure water flux was higher, which is in agreement.

\section{Conclusions}

The use of different non-solvents in the preparation of PVDF membranes caused significant differences in morphology and permeability characteristics of the membranes. The results show that:

- Different morphologies, asymmetric and symmetric membranes, can be obtained by varying the non-solvent in the coagulation bath;

- The A membrane morphology prepared in the water coagulation bath presented lower porosity and lower hydrophobicity compared to B membrane prepared in the ethanol and than water coagulation bath;

- The pure water flux and hydraulic permeability of B membrane are higher than A membrane; and

- Hydraulic resistance is the opposite of hydraulic permeability, thus the B membrane offers lower resistance to water flux.

It was concluded that the PVDF membranes prepared by the phase inversion method using different non-solvents significantly affect the membrane structure and the membrane properties.

\section{Acknowledgements}

The authors acknowledge financial support for this work from CAPES (Coordination of Improvement of Higher Level Personnel) and the Laser \& Optics Laboratory, FisNano - Institute of Physics, CNano/UFRGS.
Membrane Science. 1996; 119:269-284. http://dx.doi. org/10.1016/0376-7388(96)80001-J

6. Khayet M, Feng CY, Khulbe KC and Matsuura T. Preparation and characterization of polyvinylidene fluoride hollow fiber membranes for ultrafiltration. Polymer. 2002; 43:3879-3890. http://dx.doi.org/10.1016/S0032-3861(02)00237-9

7. Schneider K and Gassel TSV. Membrane distillation. Chemical Engineering \& Technology. 1984; 56:514-521.

8. Bonyadi S and Chung TS. Flux enhancement in membrane distillation by fabrication of dual layer hydrophilic-hydrophobic hollow fiber membranes. Journal of Membrane Science. 2007; 306:134-146. http://dx.doi.org/10.1016/j. memsci.2007.08.034

9. Wang KY, Chung TS and Gryta M. Hydrophobic PVDF hollow fiber membranes with narrow pore size distribution and ultra-thin skin for the fresh water production through membrane distillation. Chemical Engineering Science. 2008; 63:2587-2594. http://dx.doi.org/10.1016/j. ces.2008.02.020

10. Jian K and Pintauro PN. Asymmetric PVDF hollow-fiber membranes for organic/water pervaporation separations. Journal of Membrane Science. 1997; 135:41-53. http://dx.doi. org/10.1016/S0376-7388(97)00117-8

11. Li K, Kong JF, Wang D and Teo WK. Tailor-made asymmetric PVDF hollow fibers for soluble gas removal. AIChE 
Journal. 1999; 45:1211-1219. http://dx.doi.org/10.1002/ aic.690450607

12. Atchariyawut $S$, Feng $C$, Wang R, Jiraratananon $R$ and Liang DT. Effect of membrane structure on mass-transfer in the membrane gas-liquid contacting process using microporous PVDF hollow fibers. Journal of Membrane Science. 2006; 285:272-281. http://dx.doi.org/10.1016/j. memsci.2006.08.029

13. Lin DJ, Chang CL, Huang FM and Cheng LP. Effect of salt additive on the formation of microporous poly(vinylidene fluoride) membranes by phase inversion from $\mathrm{LiClO}_{4} /$ water/ DMF/PVDF system. Polymer. 2003; 44:413-422. http://dx.doi. org/10.1016/S0032-3861(02)00731-0

14. Yeow ML, Liu YT and Li KJ. Morphological study of poly(vinylidene fluoride) asymmetric membranes: Effects of the solvent, additive and dope temperature. Journal of Applied Polymer Science. 2004; 92:1782-1789. http://dx.doi. org/10.1002/app.20141

15. Wang D, Li K and Teo WK. Porous PVDF asymmetric hollow fiber membranes prepared with the use of small molecular additives. Journal of Membrane Science. 2000; 178:13-23. http://dx.doi.org/10.1016/S0376-7388(00)00460-9

16. Deshmukh SP and Li K. Effect of ethanol composition in water coagulation bath on morphology of PVDF hollow fiber membranes. Journal of Membrane Science. 1998; 150:75-85. http://dx.doi.org/10.1016/S0376-7388(98)00196-3

17. Cheng LP. Effect of temperature on the formation of microporous PVDF membranes by precipitation from 1-octanol/DMF/PVDF and water/DMF/PVDF systems. Macromolecules. 1999; 32:6668-6674. http://dx.doi. org/10.1021/ma9904181

18. Cheng LP, Young TH, Fang L and Gau JJ. Formation of particulate microporous poly(vinylidene fluoride) membranes by isothermal immersion precipitation from the 1- octanol/ dimethylformamide/poly(vinylidene fluoride) system. Polymer. 1999; 40:2395-2403. http://dx.doi.org/10.1016/ S0032-3861(98)00462-5

19. Gugliuzza A, Ricca F and Drioli E. Controlled pore size, thickness and surface free energy of super-hydrophobic PVDF ${ }^{\circledR}$ and Hyflon ${ }^{\circledR}$ AD membranes. Desalination. 2006; 200:26-28. http://dx.doi.org/10.1016/j.desal.2006.03.229

20. Gugliuzza A and Drioli E. PVDF and HYFLON AD membranes: ideal interfaces for contactor applications. Journal of Membrane Science. 2007; 300:51-62. http://dx.doi. org/10.1016/j.memsci.2007.05.004

21. Baroña GNB, Cha BJ and Jung B. Negatively charged poly(vinylidene fluoride) microfiltration membranes by sulfonation. Journal of Membrane Science. 2007; 290:46-54. http://dx.doi.org/10.1016/j.memsci.2006.12.013

22. Kuo CY, Lin HN, Tsai HA, Wang DM and Lai JY. Fabrication of a high hydrophobic PVDF membrane via non-solvent induced phase separation. Desalination. 2008; 233:40-47. http://dx.doi.org/10.1016/j.desal.2007.09.025
23. American Society for Testing and Materials - ASTM. ASTM D792: Standard Test Methods for Density and Specific Gravity (Relative Density) of Plastics by Displacement. American Standard Methods; 2008.

24. Wang X, Zhang L, Sun D, An Q and Chen H. Formation mechanism and crystallization of poly(vinylidene fluoride) membrane via immersion precipitation method. Desalination. 2009; 236:170-178. http://dx.doi.org/10.1016/j. desal.2007.10.064

25. Wenzel N. Resistance of solid surfaces to wetting by water. Industrial \& Engineering Chemistry. 1936; 28:988-994. http:// dx.doi.org/10.1021/ie50320a024

26. Wenzel RN. Surface Roughness and Contact Angle. Journal of Physical Chemistry. 1949; 53:1466-1467. http://dx.doi. org/10.1021/j150474a015

27. Cassie ABD. Contact Angles. Discussions of the Faraday Society. 1948; 3:11-16. http://dx.doi.org/10.1039/df9480300011

28. Furmidge CGLJ. The sliding of liquid drops on solid surfaces and a theory for spray retention. Journal of Colloid Science. 1962; 17:309-324. http://dx.doi. org/10.1016/0095-8522(62)90011-9

29. Bottino A, Camera-Rodab G, Capannelli G and Munari S. The formation of microporous polyvinylidene difluoride membranes by phase separation. Journal of Membrane Science. 1991; 57:1-20. http://dx.doi.org/10.1016/ S0376-7388(00)81159-X

30. Young TH, Cheng LP, Lin DJ, Fane L and Chuang WY. Mechanisms of PVDF membrane formation by immersion-precipitation in soft (1-octanol) and harsh (water) nonsolvents. Polymer. 1999; 40:5315-5323. http://dx.doi. org/10.1016/S0032-3861(98)00747-2

31. Li Q, Xu ZL and Liu M. Preparation and characterization of PVDF microporous membrane with highly hydrophobic surface. Polymers for Advanced Technolologies. 2011; 22: 520-531. http://dx.doi.org/10.1002/pat.1549

32. Tomaszewska M. Preparation and properties of flat-sheet membranes from poly(vinylidene fluoride) for membrane distillation. Desalination. 1996; 104:1-11. http://dx.doi. org/10.1016/0011-9164(96)00020-3

33. Chuang WY, Young TH, Chiu WY and Lin CY. The effect of polymeric additives on the structure and permeability of poly(vinyl alcohol) asymmetric membranes. Polymer. 2000; 41:5633-5641. http://dx.doi.org/10.1016/ S0032-3861(99)00818-6

34. Lin FC, Wang DM and Lai JW. Asymmetric TPX membranes with high gas flux. Journal of Membrane Science. 1996; 110:25-36. http://dx.doi.org/10.1016/0376-7388(95)00211-1

35. Mulder M. Basic principles of membrane technology. 2nd ed. Dordrecht: Kluwer Academic Publishers; 1996. http://dx.doi. org/10.1007/978-94-009-1766-8

36. Scott K. Handbook of industrial membranes. Oxford: Elsevier Advanced Tecnology; 1995. 